At his final admission, 2 years after MVR, he returned for fever and oliguria of nearly 2 weeks' standing. Routine blood tests showed the total number of leukocytes to be $2.3 \times 10^{9}$ cells/L. Neutrophil ratio was $78.3 \%$, and blood eosinophilic count was normal. The serum creatinine value was $142 \mu \mathrm{mol} / \mathrm{L}$. TTE showed the bioprosthetic valve to be in good condition; however, the left ventricular apex was attached with a single hyperechoic group about $1 \mathrm{~cm}$ in diameter. It had significant activity (Figure 2,C). This time, infective endocarditis was diagnosed. Although blood bacterial culture results were negative, we used cephalosporins and vancomycin to treat empirically. One week after admission, the patient's state was getting worse. Serum creatinine value reached $417 \mu \mathrm{mol} / \mathrm{L}$. Worse, he suddenly became comatose. Brain computed tomographic scan showed cerebral infarction next to the posterior horn of the left frontal lateral ventricle. The patient appeared to be in respiratory failure, and we had to use ventilator therapy. Unfortunately, he died of multiple organ failure 31 hours later.

\section{DISCUSSION}

Cardiac involvement in IHES is characterized by necrosis from infiltration of eosinophils and thrombus formation and, in the late stage, by fibrosis and chronic valvular regurgitation. ${ }^{3}$ Surgical intervention for progressive valvular dysfunction may become necessary. The experience with valve replacement in patients with IHES is limited by the rarity of the disease. Damaged valves can be replaced with mechanical or bioprosthetic valves. Despite anticoagulation, however, mechanical valve replacement may carry a high incidence of thrombosis, whereas bioprosthetic valves may require more frequent replacement for deterioration. In the limited number of patients reported with mechanical valve obstructive thrombosis, reoperation was associated with high mortality. Obstruction of mechanical valves may occur rapidly and in some cases has been reported to develop within days to months of surgery. ${ }^{4}$ Because of these concerns, the use of bioprosthetic valves has been advocated. ${ }^{5}$

This case is significant because it fulfills all the main criteria of IHES. In our case, we prescribed therapy with prednisolone and cyclosporine before surgical intervention. Prednisolone and cyclosporine did not appear to resolve the cardiac valve involvement, the eosinophil counts in peripheral blood and bone marrow, or the symptoms. After MVR with a bioprosthesis, the patient had a normal lifestyle. What is interesting is not only the rarity of the case but the rewarding response in relief of symptoms and a possible cure. Unfortunately, the patient died of infective endocarditis-associated complications 2 years after MVR. This may have been associated with long-term steroid or chemotherapeutic agent use, causing the patient's immune function disorders.

\section{References}

1. Osowo A, Fetten J, Navaneethan S. Idiopathic hypereosinophilic syndrome: a rare but fatal condition presenting with common symptoms. South Med J. 2006;99: $188-9$.

2. Harley JB, McIntosh CL, Kirklin JJ, Maron BJ, Gottdiener J, Roberts WC, et al Atrioventricular valve replacement in the idiopathic hypereosinophilic syndrome. Am J Med. 1982;73:77-81.

3. Madhwal S, Goldberg J, Barcena J, Guha A, Gogate P, Cmolik B, et al. Unusual cause of acute mitral regurgitation: idiopathic hypereosinophilic syndrome. Ann Thorac Surg. 2012;93:974-7.

4. Mizota T, Miyawaki I, Enoki T, Nakao S. Massive prosthetic valve thrombus in a patient with idiopathic hypereosinophilic syndrome. J Cardiothorac Vasc Anesth. 2007;21:434-5.

5. Watanabe K, Tournilhac O, Camilleri LF. Recurrent thrombosis of prosthetic mitral valve in idiopathic hypereosinophilic syndrome. J Heart Valve Dis. 2002; 11:447-9.

\title{
Development of a life-threatening mediastinal hematoma from a ruptured bronchial artery aneurysm
}

\author{
Hee Jung Kim, MD, ${ }^{a}$ Ho Sung Son, MD, PhD, ${ }^{a}$ Sung Bum Cho, MD, PhD, ${ }^{b}$ and Kwang Taik Kim, MD, \\ $\mathrm{PhD},{ }^{\mathrm{a}}$ Seoul, South Korea
}

\footnotetext{
From the Department of Thoracic and Cardiovascular Surgery, ${ }^{\mathrm{a}}$ College of Medicine, Korea University, Seoul, South Korea; and the Department of Radiology, ${ }^{b}$ College of Medicine, Korea University, Seoul, South Korea.

Disclosures: Authors have nothing to disclose with regard to commercial support.

Received for publication June 4, 2013; revisions received July 1, 2013; accepted for publication July 12, 2013; available ahead of print Sept 11, 2013

Address for reprints: Ho Sung Son, MD, PhD, Department of Thoracic and Cardiovascular Surgery, College of Medicine, Korea University, 73 Inchon-ro, Sungbuk-gu, Seoul 136-705, South Korea (E-mail: hssonmd@korea.ac.kr).

J Thorac Cardiovasc Surg 2013;146:e47-9

$0022-5223 / \$ 36.00$

Copyright (C) 2013 by The American Association for Thoracic Surgery

http://dx.doi.org/10.1016/j.jtcvs.2013.07.034
}

Mediastinal bronchial artery aneurysm (BAA) is a rare condition. $^{1-4}$ It is detected in fewer than $1 \%$ of all patients who undergo selective bronchial arteriography. ${ }^{1}$ The clinical manifestation of BAA depends on size, location, and concomitant disease. ${ }^{4}$ Rupture can result in serious complications, such as life-threatening hemorrhage.

We report the case of a 79-year-old woman who was treated with transcatheter embolization and surgical removal of a mediastinal hematoma resulting from the life-threatening rupture of a BAA. 


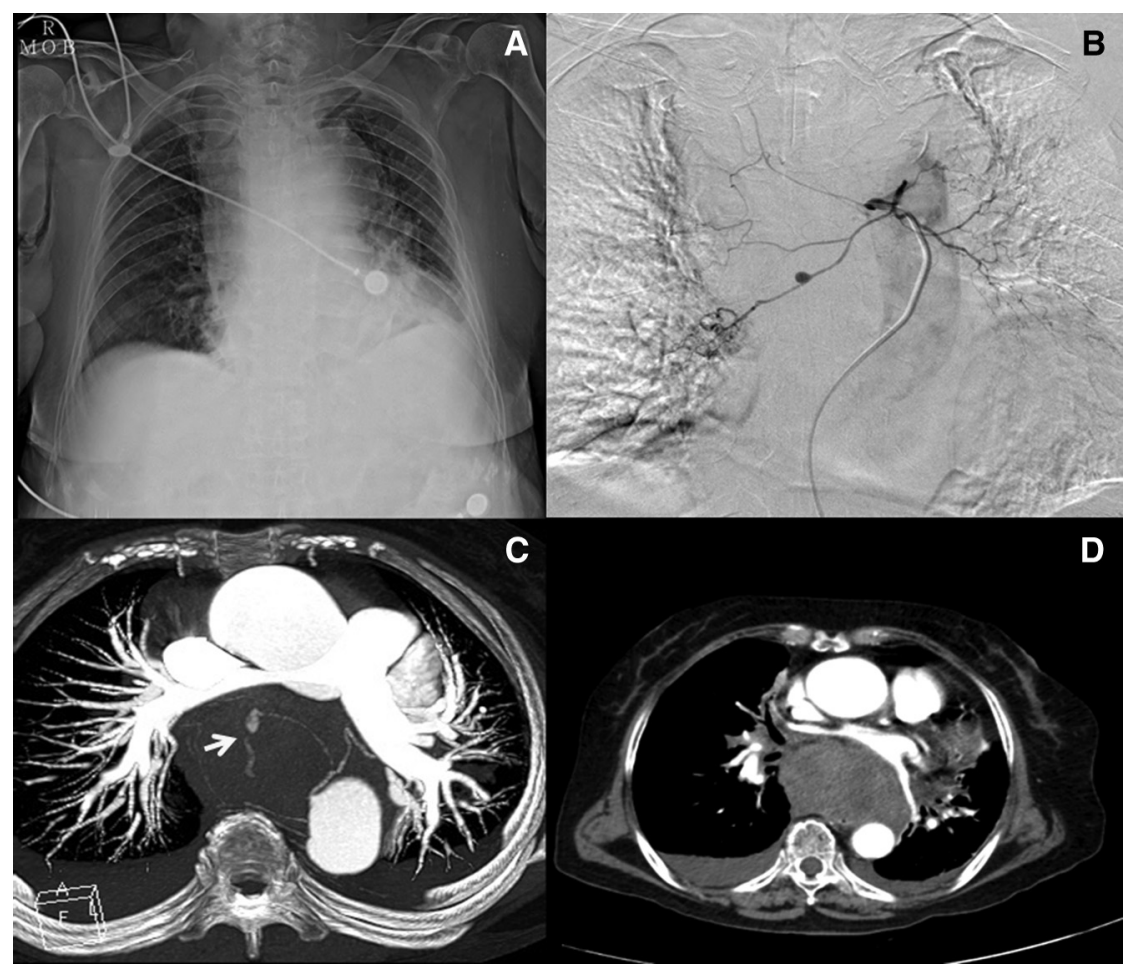

FIGURE 1. A, Chest radiograph showing mediastinal widening. B, Selective bronchial arteriogram showing a small pseudoaneurysm on the right bronchial artery. $\mathrm{C}$ and $\mathrm{D}$, Chest computed tomographic image depicting the compression of the left atrium and right pulmonary artery by the mediastinal hematoma. In addition, contrast medium leakage was noted from the right bronchial artery aneurysm (arrow).

\section{CLINICAL SUMMARY}

A 79-year-old woman came to our emergency department with sudden-onset chest tightness, dysphagia, sudden-onset substernal chest pain, and epigastric discomfort, which had started 2 hours previously. When the patient arrived at the emergency department, her heart rate was 104 beats/min, her respiratory rate was 22 breaths/min, her blood pressure was $160 / 100 \mathrm{~mm} \mathrm{Hg}$, and her and body temperature was $36.3^{\circ} \mathrm{C}$. She had no hypertension, and there were no specific findings in her medical history. Chest physical examination revealed a regular sinus rhythm of the heart, tachycardia, no cardiac murmur, and smooth breathing sounds in both lung fields.

A complete blood cell count indicated an increased white blood cell count of $14.4 \times 10^{9}$ cells/L but normal hemoglobin $(12.3 \mathrm{~g} / \mathrm{dL})$ and hematocrit $(36.2 \%)$ values. Chest radiography revealed pulmonary congestion and mediastinal widening (Figure 1,A). The patient underwent computed tomography for aortic assessment. The computed tomographic image showed a large amount of hematoma in the mediastinum, a compressed left atrium, and a suspected BAA rupture (Figure 1, $C$ and $D$ ). The BAA measured about $7 \mathrm{~mm}$. Transthoracic echocardiography was performed to exclude other cardiac diseases. The transthoracic echocardiographic image showed the left atrium to be compressed severely by the round extracardiac mass and preserved left ventricular function. During the transthoracic echocardiographic examination, the blood pressure and level of consciousness of the patient deteriorated. She recovered after an epinephrine injection but had recurrences of the unstable vital signs several times before the operation. We planned transcatheter embolization and surgical removal of the mediastinal hematoma. First, thoracic aortography was performed, confirming the suspected ruptured BAA (Figure 1, B). Transcatheter coil and gelfoam embolizations were performed immediately by an interventional radiologist. After general anesthesia induction through a doublelumen endobronchial tube, the surgical operation was started with the patient in the left-side down decubitus position. During the video-assisted thoracoscopic surgical drainage, the systolic blood pressure of the patient decreased continuously to $60 \mathrm{~mm} \mathrm{Hg}$. We converted to right thoracotomy and removed the hematoma successfully. The patient recovered without any complications and was discharged from the hospital. During the 1-year follow-up period, the patient had an uneventful postoperative course without any complications.

\section{DISCUSSION}

BAA is a rare cause of mediastinal hemorrhage; however, a ruptured BAA can cause massive bleeding or lifethreatening complications. The exact etiology of BAA is 
unclear, although it is generally considered a result of increased blood flow to the lungs or weakening of the vessel wall. When associated with pulmonary sequestration and agenesis, BAA is considered congenital. It also may be acquired, arising in response to inflammatory lung disease, bronchiectasis, atherosclerosis, tuberculosis, or trauma. A systemic vascular abnormality has been described in BAA, such as Osler-Weber-Rendu disease. The location of the BAA is classified as either mediastinal or intrapulmonary. Mediastinal BAAs have multiple symptoms, including compression or rupture into contiguous anatomic structures (the esophagus, trachea, bronchus, superior vena cava, and heart). In contrast, hemoptysis is the most common symptom of intrapulmonary BAA. ${ }^{3,4}$

Kalangos and colleagues ${ }^{3}$ summarized 15 cases of reported BAA. Mean size of the BAAs in their series was $12.8 \mathrm{~mm}(5-30 \mathrm{~mm})$. Our case demonstrates that even a small BAA $(7 \mathrm{~mm})$ can have a life-threatening rupture. BAA thus should be treated regardless of size or symptoms. Two treatment approaches have been used for BAA. One is an interventional approach with transcatheter bronchial artery embolization. This has been increasingly used to treat BAA because it is less invasive. Aorta stent-graft placement is also a good technique for the treatment of BAA. The other is a surgical approach with ligation or resection for the removal of lesions. The surgical approach is especially effective for a ruptured BAA. In cases with massive bleeding, cardiopulmonary bypass is helpful to treat uncontrollable bleeding. ${ }^{2-5}$

In our case, the BAA was ruptured, and massive bleeding occurred in the mediastinum. A huge hematoma was compressed to the left atrium, causing the unstable vital signs. Before surgery, we performed selective bronchial artery angiography to identify the ruptured part accurately and thus prevent uncontrollable bleeding during the surgery. After successful transcatheter bronchial artery embolization, the hematoma was surgically removed.

\section{References}

1. Fujita J, Akashi K, Kunikane H, Nakajima I, Saito S, Abe S, et al. [A case of bronchial artery aneurysm demonstrating a mass shadow on chest X-ray film]. Nihon Kyobu Shikkan Gakkai Zasshi. 1991;29:1591-5. Japanese.

2. Hu CX, Huang S, Xu ZW, Chen W, Huang JS, Fu Z. Combination of aortic stent-graft and arterial embolization for ruptured bronchial artery aneurysm. Ann Thorac Surg. 2011;92:e19-21.

3. Kalangos A, Khatchatourian G, Panos A, Faidutti B. Ruptured mediastinal bronchial artery aneurysm: a dilemma of diagnosis and therapeutic approach. J Thorac Cardiovasc Surg. 1997;114:853-6.

4. Tanaka K, Ihaya A, Horiuci T, Morioka K, Kimura T, Uesaka T, et al Giant mediastinal bronchial artery aneurysm mimicking benign esophageal tumor: a case report and review of 26 cases from literature. J Vasc Surg. 2003; $38: 1125-9$.

5. Sanchez E, Alados P, Zurera L, Canis M, Munoz I, Casares J, et al. Bronchial artery aneurysm treated with aortic stent graft and fibrin sealant. Ann Thorac Surg. 2007;83:693-5.

\title{
From relapsing polychondritis to extracorporeal membrane oxygenation
}

\author{
Delphine Mitilian, MD, ${ }^{\mathrm{a}}$ François Gonin, MD, ${ }^{\mathrm{a}}$ Edouard Sage, MD, ${ }^{\mathrm{a}}$ and Sylvain Beurtheret, MD, \\ Suresnes and Marseille, France
}

Relapsing polychondritis (RP) is a multisystem inflammatory disease of unknown etiology affecting mainly chondritis of auricular, nasal and tracheal cartilage. Recurrent episodes of inflammation result in cartilage destruction and malacia of the airways. It often requires challenging

\footnotetext{
From the Department of Thoracic Surgery and Lung Transplantation, ${ }^{\mathrm{a}}$ Foch Hospital, Université de Médecine Paris-Île-de-France-Ouest, Suresnes, France; and the Department of Cardiac Surgery, ${ }^{\text {b }}$ Saint Joseph Hospital, Marseille, France. Disclosures: Authors have nothing to disclose with regard to commercial support. Received for publication March 7, 2013; revisions received June 16, 2013; accepted for publication July 3, 2013; available ahead of print Aug 30, 2013.

Address for reprints: Delphine Mitilian, MD, Department of Thoracic Surgery, Hôpital Foch, 40 rue Worth 92150 Suresnes, France (E-mail: dmitilian@gmail. com).

J Thorac Cardiovasc Surg 2013;146:e49-51

$0022-5223 / \$ 36.00$

Copyright (C) 2013 by The American Association for Thoracic Surgery

http://dx.doi.org/10.1016/j.jtcvs.2013.07.016
}

endoscopic stent placement. We report the case of an extended tracheal and bronchial membranous laceration treated conservatively, with a total weaning from mechanical ventilation thanks to venovenous extracorporeal membrane oxygenation (ECMO).

\section{CLINICAL SUMMARY}

A 41-year-old man with a diagnosis of RP underwent an elective tracheobronchial endoscopy. Because of the global airway malacia, Y-prosthesis placement was attempted. The procedure was complicated by bronchial edema and perforation of the tracheal membranous wall extending from the carina to the main bronchi, leading to bilateral tension pneumothorax and hemodynamic instability. The situation was initially stabilized by insertion of a single tracheal prosthesis, allowing safe intubation and by 